\title{
CONTRIBUIÇÃO DO PORTAL DE PERIÓDICOS DA CAPES PARA A PRODUÇÃO CIENTÍFICA DOS PESQUISADORES BRASILEIROS NO CAMPO DO DIREITO
}

\author{
um estudo bibliométrico
}

\author{
Eliane Gomes ${ }^{1}$ \\ Universidade Federal do Rio de Janeiro \\ elianeagomes@gmail.com
}

Nanci Oddone $e^{2}$

Universidade Federal do Estado do Rio de Janeiro neoddone@unirio.br

\begin{abstract}
Resumo
Os conceitos de política de informação e de ciclo de políticas públicas oferecem suporte à constatação de que o Portal de Periódicos da Capes representa o instrumento de uma política pública de acesso à informação científica que modificou o regime de informação até então vigente. Nesse contexto, para avaliar a legitimidade dessa mudança política que afetou diretamente as funcionalidades da comunicação científica no país, o presente estudo fez uso de técnicas bibliométricas com o objetivo de aferir qual foi a contribuição dos periódicos estrangeiros assinados pelo Portal na área do Direito para a produção dos pesquisadores brasileiros dessa área. A população da pesquisa envolveu os docentes permanentes dos Programas de Pós-Graduação em Direito que obtiveram notas 4, 5 e 6 na Avaliação Trienal de 2013. Sua produção foi examinada, incluindo os artigos científicos publicados no exterior, e todas as citações a artigos estrangeiros foram extraídas, formando uma listagem de títulos estrangeiros que em seguida foi comparada com a listagem de títulos assinados pelo Portal visando definir indicadores de demanda versus oferta de títulos. Os resultados mostraram que os pesquisadores da área do Direito utilizaram apenas 7,6\% dos títulos estrangeiros disponíveis no Portal, investindo mais em títulos com acesso aberto e em formato impresso.
\end{abstract}

Palavras-chave: Portais. Políticas de informação. Periódicos científicos.

\section{THE CONTRIBUTION OF THE CAPES PORTAL OF SCIENTIFIC JOURNALS TO THE SCIENTIFIC PRODUCTION OF BRAZILIAN RESEARCHERS IN THE FIELD OF LAW}

a bibliometric study

\begin{abstract}
The concepts of information policy and of public policies cycle give support to the idea that the Portal Periódicos Capes represents the instrument of a public policy of access to scientific information that modified the information regime in force until then. In this context, to assess the legitimacy of this political change that directly affected the functionalities of scholarly communication in the country, this study used bibliometric techniques in order to assess the contribution of foreign journals subscribed by the Portal in the area of Law to the production of Brazilian researchers in this area. The research population involved permanent professors from the Law Graduate Programs who obtained grades 4, 5 and 6 in the 2013 Triennial Evaluation. Their production was examined, including scientific articles published abroad, and all citations to foreign articles were extracted, forming a list of foreign journal titles that was then compared with the list of journals signed by the Portal, aiming to define demand versus supply indicators. The results have shown that researchers in the field of Law used only $7.6 \%$ of foreign titles available on the Portal, investing more in open access and print format journal titles.
\end{abstract}

Keywords: Portals. Information policies. Scientific journals.

\footnotetext{
${ }^{1}$ Doutoranda em Ciência da Informação PPGCI/IBICT/UFRJ; Mestre em Biblioteconomia PPGB/UNIRIO; Bibliotecária da Universidade Federal do Rio de Janeiro.

${ }^{2}$ Doutorado em Ciência da Informação pela Universidade Federal do Rio de Janeiro. Professora da Universidade Federal do Estado do Rio de Janeiro
} 


\section{ARTIGO}

INOVAÇÃo

\section{INTRODUÇÃO}

Criado em 2000, o Portal de Periódicos da Capes engloba uma ampla cobertura da literatura internacional destinada à comunidade de pesquisadores de todas as áreas. Seu acesso é voltado a pesquisadores de instituições de ensino e pesquisa de todas as regiões do país. $\mathrm{O}$ Portal de Periódicos da Capes é muito mais do que uma biblioteca digital federada, heterogênea e distribuída (FERREIRA; SOUTO, 2006), ele aparelha uma política pública de acesso democrático ao conhecimento científico, visando alcançar uma maior produtividade científica nacional, possibilitando uma internacionalização das pós-graduações brasileiras (ALMEIDA; GUIMARÃES; ALVES, 2010).

A idealização do Portal visava à superação do impasse financeiro proporcionado pela dispendiosa manutenção das coleções científicas nas instituições de pesquisas nacionais; a contenção dos recursos financeiros destinados a essa manutenção; o acentuado crescimento dos valores cobrados pelas editoras científicas aos assinantes de periódicos impressos. Além disso, o modelo de negócio estabelecido pelo projeto do Portal responde a um novo regime de informação (GONZÁLEZ DE GOMÉZ, 2012), que destaca uma tendência do mercado internacional em ofertar pacotes de periódicos em formato eletrônico com acesso restrito e padrões proprietários, proporcionando uma maior participação das editoras na distribuição do conhecimento científico (AMORIM, 2002; CORREA et al., 2008; ORTELLADO, 2008).

A área do Direito iniciou tardiamente a sua comunicação científica. Os periódicos jurídicos acadêmicos se consolidaram no Brasil após a instituição do ensino superior no país (FONSECA, 2009). Os periódicos jurídicos nasceram na Europa com a finalidade de disseminar as novas informações resultantes da ruptura metodológica, proveniente dos argumentos racionais que se contrapuseram aos argumentos absolutistas defendidos pelas universidades europeias até então. Atualmente, a pesquisa jurídica adquiriu um caráter interdisciplinar, o que evidencia sua necessidade ao acesso à produção científica internacional, tanto para publicar suas pesquisas como também para citar o que já foi produzido. Desta forma, o Portal de Periódicos da Capes é uma fonte importante de pesquisa.

Neste cenário, a presente pesquisa teve como questão de partida: Qual a participação dos títulos estrangeiros disponíveis no Portal de Periódicos da Capes na produção científica dos pesquisadores da área do Direito durante o triênio 2010-2012?

Para responder esse questionamento foi necessário levantar quais títulos de periódicos o Portal oferecia à comunidade científica da área do Direito, identificar em quais periódicos 
essa comunidade publicou seus resultados científicos e quais títulos de periódicos são citados por esses pesquisadores em seus artigos.

Desta forma, o objetivo desta pesquisa é mensurar a contribuição dos títulos estrangeiros disponíveis no Portal de Periódicos da Capes na produção científica dos pesquisadores da área do Direito durante o triênio 2010-2012.

\section{AS POLÍTICAS PÚBLICAS QUE DIRECIONARAM A IMPLEMENTAÇÃO DO PORTAL DE PERIÓDICOS DA CAPES}

O papel de elaborador e implementador das políticas públicas de ciência e tecnologia foram assumidos pelo Estado a partir da década de 1950 (GONZALEZ DE GÓMEZ, 2002). Com a criação em 1951 da Coordenação de Aperfeiçoamento de Pessoal de Nível Superior (Capes) e do Conselho Nacional de Desenvolvimento Científico e Tecnológico (CNPq) estabeleceu-se um regime de informação que apontou demandas de acesso à informação científica por parte da comunidade científica que estava em constante crescimento. O Instituto Brasileiro de Bibliografia e Documentação (IBBD), criado em 1954, procurou reduzir as dificuldades encontradas pelos pesquisadores, mas os obstáculos se ampliaram nas décadas seguintes.

Na década de 1970 apareceram programas governamentais que procuraram estabelecer os parâmetros para a definição de uma política pública e a realização de um sistema de informação científica e tecnológica (ICT), com a criação de mecanismos financeiros para apoio (Programa de Metas e Bases para a Ação do Governo - 1970-1972); e planos que visavam consolidar a infraestrutura de pesquisa científica (I Plano Nacional de Desenvolvimento (PND) e I Plano Básico de Desenvolvimento Científico e Tecnológico (PBDCT) - 1972-1974) e fortalecer a ciência e a tecnologia para modernizar a indústria, a economia e a sociedade (II PND e II PBDCT - 1975-1979).

De acordo com González de Gómez (2002) as políticas de informação científica eram indiretas, tácitas e "frequentemente [...] deslocadas, de acordo com definições de prioridades conjunturais e em constantes mudanças" (GONZÁLEZ DE GÓMEZ, 2002, p.29). A partir da emergência das tecnologias eletrônicas de informação e comunicação, "o discurso dos sistemas nacionais de informação científica e tecnológica, colocado como questão de Estado, começava a ser substituído por um discurso de cunho econômico" (GONZÁLEZ DE GÓMEZ, 2002, p. 29). 
Desta forma, a preocupação com infraestruturas de armazenamento, tratamento e recuperação da informação são substituídos pela adoção de uma lógica de mercado, orientada pelo conceito de Sociedade da Informação, o qual

indica o atributo de uma forma específica de organização social em que a geração, o
processamento e a transmissão da informaçãa tornam-se as fontes fundamentais de
produtividade e poder devido às novas condições tecnológicas surgidas nesse período
histórico (CASTELLS, 2012, p. 65).

Criado 1986 no âmbito da Secretaria da Educação Superior (SESu) do Ministério da Educação (BRASIL, 1986a, 1986b, 1986c), o Programa Nacional de Bibliotecas Universitárias (PNBU) é reconhecido na área da Biblioteconomia como a primeira política pública brasileira voltada ao desenvolvimento de coleções de Bibliotecas. A criação do PNBU foi influenciada pelo fortalecimento da pós-graduação durante a década de 1970; pelos intensos debates, a partir de 1978, realizados pelas edições do Seminário Nacional de Bibliotecas Universitárias (SNBU); e pela crise econômica dos anos de 1980 (GARCIA, 1980; CHASTINET, 1990; LUBISCO, 2011, CUNHA; DIÓGENES, 2016).

A criação do PNBU parece constituir o que Leonardo Secchi (2014), dentro do ciclo de políticas públicas, conceitua como a etapa de identificação do problema, quando uma situação indesejada é detectada, verificando-se a viabilidade de sua solução. Muitos autores (GARCIA, 1991; LUBISCO, 2011; SILVA, 2009; SILVA, 2010; CAETANO, 2012; CUNHA; DIÓGENES, 2016) evidenciaram a importância do PNBU e seu impacto para o desenvolvimento das coleções das bibliotecas universitárias enquanto primeira política nacional direcionada a essas instituições, ressaltando seus efeitos: estímulo às pesquisas e a ampliação da produção científica do país.

A partir de 1990 o PNBU/Probib sofreu uma desaceleração, que resultou na divisão de suas atribuições e na diminuição dos recursos do governo federal para a renovação das assinaturas de periódicos. Com isso, as universidades tiveram que assumir a renovação e a assinatura com recursos próprios. Os altos custos dessas assinaturas e as verbas insuficientes acabaram por impedir a renovação de uma parte dos títulos e a assinatura de novos periódicos (ODDONE; MEIRELLES, 2006; FERNANDES; CENDÓN, 2010). Em 1995, tentando garantir a assinatura dos volumes referentes a 1995 e complementar as coleções interrompidas nos anos anteriores, a Capes criou o Programa de Apoio à Aquisição de Periódicos (PAAP), mas a falta de recursos nos anos seguintes agravou o problema (ODDONE; MEIRELLES, 2006).

No ciclo de políticas públicas a etapa seguinte à identificação do problema é a formulação de alternativas. Na literatura foram identificadas duas alternativas formuladas pela 
INOVAÇÃo

Capes para manter o acervo de periódicos científicos das bibliotecas universitárias. A primeira alternativa foi instigada pela experiência europeia dos Centros de Referência Regional, que reuniam coleções de periódicos impressos e serviam de base para a comutação bibliográfica com outras bibliotecas daqueles países. A segunda alternativa foi influenciada pelo Programa Biblioteca Eletrônica (Probe), criado em 1999 pelas bibliotecas universitárias paulistas com financiamento da Fundação de Amparo à Pesquisa do Estado de São Paulo (FAPESP). O Probe era um consórcio de bibliotecas com o objetivo de oferecer acesso ao texto completo de artigos de periódicos científicos em meio eletrônico, via $C D$-Rom, armazenados em um servidor local e acessados pela rede (FERNANDES; CENDÓN, 2010; CORREA et al., 2008).

A fase subsequente do ciclo de políticas públicas, de acordo com Secchi (2014), é a tomada de decisão, geralmente influenciada pelos grupos de interesse envolvidos. No caso da nova política que resultou no Portal Periódicos Capes, esses grupos eram formados pela Associação Nacional dos Dirigentes das Instituições Federais de Ensino Superior (Andifes), Sociedade Brasileira para o Progresso da Ciência (SBPC) e Comissão Brasileira de Bibliotecas Universitárias (CBBU), que incentivavam a proposta da assinatura de periódicos eletrônicos. Secchi (2014) explica que após a tomada de decisão, a política é construída, ou seja, suas regras, rotinas e processos são transformados em ações concretas. Nessa direção, foi a partir da Portaria $\mathrm{n}^{\circ}$ 34, de 19 de julho de 2001, que a Capes reformulou o PAAP, estabelecendo um novo formato para a aquisição e uso dos periódicos científicos estrangeiros nas bibliotecas universitárias brasileiras e legitimando o recém-lançado Portal, como uma política pública de acesso à informação científica em âmbito nacional (ALMEIDA; GUIMARÃES, 2013).

\section{A DISSEMINAÇÃO DA PESQUISA JURÍDICA NO BRASIL: OS PERIÓdICOS ACADÊMICOS}

Até o século XVIII, os juristas acreditavam que, por ser uma necessidade prática e por conta de seus atores já conhecerem os dados precisos para o seu desenvolvimento, a área do Direito não necessitava publicar em periódicos científicos. Suas formas de comunicação se reduziam às compilações monográficas de leis e jurisprudências e às obras elementares (MARTINHO, 2011). O método científico e o pensamento racionalista de Descartes, no entanto, influenciaram o rompimento do "elo entre a jurisprudência e a dogmática fundada na autoridade dos textos romanos" (FERRAZ JUNIOR, 2015, p. 44).

A partir do final do século XVIII, portanto, com a quebra do paradigma metodológico absolutista e a ideia de que os argumentos racionais deveriam prevalecer, o periódico científico 
passou a ter maior relevância para os juristas, que assumiram o papel do ser humano como centro da emanação das leis. Os juristas sentiram a necessidade de disseminar suas novas ideias e conquistar adeptos ao novo pensamento em que a égide das normas e das leis era constituída pela razão e não por uma emanação divina (RAMOS, 2010).

$\mathrm{Na}$ Europa, os primeiros periódicos jurídicos surgiram no final do século XVIII na França. Em 1835, surge em Portugal a primeira revista jurídica editada pela Sociedade Jurídica Lisboense (CHORÃO, 2002; FORMIGA, 2010; RAMOS, 2010). No Brasil, a primeira revista jurídica é criada em 1843, sendo a precursora do Diário Oficial, pois trazia em suas seções publicações de atos oficiais governamentais. A consolidação das revistas científicas acadêmicas e das revistas jurisprudenciais ocorrem com a implantação do ensino superior brasileiro (FORMIGA, 2007).

Mais recentemente, a partir de meados do século $\mathrm{XX}$, a influência da interdisciplinaridade na pesquisa jurídica proporcionou que a pesquisa empírica fosse enfatizada e motivou que a área do Direito buscasse recursos metodológicos e fundamentos empíricos de outros campos científicos. A produção da área tornou-se crítica, não se esgotando no âmbito da dogmática jurídica, mas submetendo "o conjunto de conceitos e categorias dogmáticas ao crivo de critérios de legitimidade e eficácia social” (FONSECA, 2009, p. 41).

Os periódicos jurídicos, atualmente, podem ser classificados em quatro tipos: (a) as revistas gerais ou generalistas, que se dedicam aos diversos ramos do Direito, incluindo artigos com temáticas variadas; (b) as revistas especializadas, que se dedicam a estudar uma disciplina jurídica específica e aparecem para suprir a falta de títulos especializados nesses ramos; (c) as revistas acadêmicas ou universitárias, que são vinculadas a uma instituição de ensino, possuem colaboradores que são alunos e professores desta instituição e cujos artigos envolvem mais teoria jurídica, doutrina, seções de legislação, jurisprudência crítica ou fatos relevantes à vida acadêmica; (d) os boletins ou newsletters, que são de responsabilidade das associações profissionais de âmbito jurídico, sociedades de advogados ou outras instituições jurídicas, tem curta periodicidade e seus conteúdos são informativos sobre as atividades jurídicas, as produções legislativas e jurisprudenciais (MARTINHO, 2011).

\section{ESTRATÉGIA METODOLÓGICA}

O estudo proposto insere-se na categoria de pesquisa descritiva, com abordagem quantitativa e uso de técnicas bibliométricas e estatísticas de coleta de dados, em especial a análise de citações. O recorte cronológico escolhido foi o período de 2010-2012 por se tratar 
do último triênio avaliado pela Capes, considerando que os documentos referentes a esse período já se encontravam disponíveis em linha.

Em junho de 2015, foi realizada uma consulta ao Portal de Periódicos da Capes para identificar os títulos estrangeiros disponíveis na área do Direito. A listagem foi obtida após selecionar a opção "Buscar periódicos", "Buscar por área do conhecimento", "Ciências Sociais Aplicadas" e "Direito". O inventário foi o ponto de partida para determinar os títulos estrangeiros disponibilizados no Portal mediante assinatura, com acesso restrito às instituições credenciadas.

A população estudada foram os docentes permanentes dos programas de pós-graduação em Direito (PPGDs) reconhecidos pela Capes com mestrado e doutorado simultaneamente, no triênio de 2010-2012. A relação de PPGDs recomendados pela Capes com conceitos 4, 5 e 6 foi identificada em agosto de 2015, recorrendo-se à Plataforma Sucupira (https://sucupira.capes.gov.br/sucupira/) e ao sítio da Avaliação Trienal 2013 (http://avaliacaotrienal2013.capes.gov.br/), especialmente o Painel de Divulgação dos Resultados da Trienal (https://goo.gl/uZolkZ), que permite a visualização dos dados e a aplicação de filtros por área, região, conceito e universidade.

A identificação do corpo docente dos PPGDs selecionados e sua produção científica durante o triênio 2010-2012 foi realizada a partir dos Cadernos de Indicadores (https://goo.gl/DpSEIL), um repositório mantido pela Capes que contém todos os relatórios anuais produzidos pelos programas de pós-graduação em funcionamento entre os anos de 1998 e 2012. Esses relatórios são arquivos em formato pdf que reúnem informações sobre a proposta dos programas, linhas de pesquisa, teses e dissertações defendidas, disciplinas ministradas, corpo docente, projetos de pesquisa, produção bibliográfica, produção técnica, entre outros. Para identificar os docentes que haviam sido indicados pelos PPGDs escolhidos como "permanentes" em todos os três anos do triênio foram verificados os Cadernos "CD - Corpo Docente, Vínculo Formação". Os Cadernos "PB - Produção Bibliográfica" foram utilizados para mapear a produção científica desses docentes durante o triênio, destacando os artigos completos publicados em periódicos internacionais, que fariam parte do corpus da pesquisa.

Para examinar o corpus de artigos reunidos com a finalidade de levantar as citações a artigos publicados em periódicos estrangeiros foi necessário empregar estratégias criativas a fim de localizar o texto completo de todos os artigos do corpus. As alternativas adotadas incluíram: buscas em bases e catálogos de editoras, livrarias e bibliotecas entre os quais destacaram-se: Observatorio Bibliografico del Diritto dell'Economia, Catalogo Italiano dei Periodici (ACNP), Associazione ESSPER: Periodici Italiani di Economia, Scienze Sociali e 


\section{ARTIGO}

INOVAÇÃo

Storia, Dialnet, Information Matrix for the Analysis of Journals (MIAR), Periodicals Service Company \& Schmidt Periodicals GmbH, The Keepers Registry, Cardiff Index to Legal Abbreviations; buscas no Google Scholar; buscas livres no Google; buscas em repositórios institucionais; buscas em bases de dados de acesso aberto; buscas no Catálogo Coletivo Nacional de Publicações Seriadas $(\mathrm{CCN})$ e posterior aquisição dos artigos via Programa de Comutação Bibliográfica (COMUT); pedido direto aos autores, por email. O acesso ao texto completo dos artigos do corpus permitiu que finalmente se pudesse observar suas referências e notas de rodapé para identificar os artigos de periódicos estrangeiros que haviam sido citados.

Após o mapeamento e a tabulação de todos os dados foram realizadas análises comparativas de modo a avaliar a participação dos títulos estrangeiros disponibilizados pelo Portal de Periódicos da Capes na produção científica dos pesquisadores brasileiros da área do Direito durante o triênio 2010-2012, verificando se os recursos dispendidos pela Capes na manutenção do Portal e da política nacional de acesso à informação científica têm correspondido ao interesse e às necessidades dos pesquisadores da área.

\section{RESULTADOS}

Além de artigos de periódicos científicos o Portal Periódicos Capes oferece uma diversificada gama de fontes de informação. Para esta pesquisa o objeto de interesse foram os periódicos estrangeiros, aos quais os usuários somente têm acesso mediante a assinatura pelo Portal. Em junho de 2015, após consulta ao website www.periodicos.capes.gov.br, foram identificados 982 títulos classificados para a área do Direito. No entanto, constatou-se que 17 desses títulos eram livros, 60 eram periódicos nacionais e 211 estavam disponíveis por meio de acesso aberto que, quando retirados, reduziram a listagem a um total de 694 títulos de periódicos estrangeiros aos quais os pesquisadores só teriam acesso através de assinatura. Para a compilação final, porém, decidiu-se manter os 211 títulos em acesso aberto, consolidando uma listagem com 905 periódicos estrangeiros na área do Direito.

Com relação ao idioma verificou-se que, dos 905 títulos analisados, a língua inglesa é o idioma predominante em $93 \%$ do total e os outros $7 \%$ nas demais línguas, conforme a Tabela 1.

Tabela 1 - Idiomas predominantes dos títulos estrangeiros coletados em 2015.

\begin{tabular}{lcc}
\hline IDIOMA & REGISTROS & PERCENTUAL \\
\hline Inglês & 841 & $93 \%$ \\
Espanhol & 23 & $2,50 \%$ \\
Bilíngue & 15 & $1,60 \%$
\end{tabular}

P2P \& INOVAÇÃO, Rio de Janeiro, v. 7, n. 1, p. 70-87, set. 2020/fev. 2021. 
INOVAÇÃO

\begin{tabular}{lcc} 
Alemão & 13 & $1,40 \%$ \\
Multilíngue & 5 & $0,50 \%$ \\
Francês & 4 & $0,44 \%$ \\
Croata & 1 & $0,11 \%$ \\
Grego & 1 & $0,11 \%$ \\
Português & 1 & $0,11 \%$ \\
Turco & 1 & $0,11 \%$ \\
\hline TOTAL & $\mathbf{9 0 5}$ & $\mathbf{1 0 0 \%}$ \\
\hline
\end{tabular}

Fonte: Portal de Periódicos da Capes

Os principais países de edição dos títulos disponíveis no Portal são os Estados Unidos (57\%), o Reino Unido (17\%) e a Holanda (8\%), conforme se pode ver na Tabela 2.

Tabela 2 - Distribuição geográfica das editoras dos títulos estrangeiros disponíveis em 2015.

\begin{tabular}{lcc}
\hline PAÍS & REGISTROS & PERCENTUAL \\
\hline Estados Unidos & 514 & $57 \%$ \\
Reino Unido & 152 & $17 \%$ \\
Holanda & 73 & $8 \%$ \\
Austrália & 31 & $3,40 \%$ \\
Alemanha & 30 & $3,30 \%$ \\
Canadá & 22 & $2,40 \%$ \\
Espanha & 11 & $1,20 \%$ \\
França & 11 & $1,20 \%$ \\
Outros & 61 & $6,5 \%$ \\
\hline TOTAL & $\mathbf{9 0 5}$ & $\mathbf{1 0 0 \%}$ \\
\hline
\end{tabular}

Fonte: Portal de Periódicos da Capes.

Na Tabela 3 pode-se identificar que dois modelos de negócio adotados pelos 905 títulos de periódicos estrangeiros: títulos assinados e títulos em acesso aberto. As assinaturas correspondem a $77 \%$ dos títulos disponíveis e as de acesso aberto correspondem a $23 \%$.

Tabela 3 - Modelo de negócio dos títulos estrangeiros disponíveis em 2015.

\begin{tabular}{lcc}
\hline MODELO DE NEGÓCIO & REGISTROS & PERCENTUAL \\
\hline Assinatura & 694 & $77 \%$ \\
Acesso Aberto & 211 & $23 \%$ \\
\hline TOTAL & $\mathbf{9 0 5}$ & $\mathbf{1 0 0 \%}$ \\
\hline
\end{tabular}

Fonte: Dados da pesquisa (2017). 
Para analisar a produção científica da área do Direito e levantar os periódicos estrangeiros utilizados pelos pesquisadores para publicar seus estudos, identificaram-se inicialmente 31 programas de pós-graduação em Direito (PPGDs) e 88 cursos registrados na Plataforma Sucupira em agosto de 2015. Foram descartados desse grupo os programas da Universidade Veiga de Almeida (UVA) que ainda estavam aguardando homologação pelo CNE e da UFRJ, pois o seu Doutorado ainda não tinha sido iniciado.

Desta forma, foram analisados 29 programas, sendo oito programas com nota 6 (PUC/MG, PUC/RS, UFMG, UFSC, UFPR, UNB, UNISINOS e USP), dez com nota 5 (Ciências Criminais PUC/RS, PUC/PR, UFPB JP, UFRGS, UNESA, UNICEUB, UNIFOR, UNISC, UNIVALI, UPM) e onze com nota 4 (FADISP, FDV, ITE, PUC RJ, UERJ, UFBA, UFC, UFPE, UNISANTOS, PUC/SP e UFPA), conforme demonstrado no Quadro 1.

Quadro 1 - PPGDs divididos por notas da Capes e professores do quadro permanente, 2010-2012.

\begin{tabular}{|l|l|l|l|l|c|}
\hline $\begin{array}{l}\text { Universidades } \\
\text { Nota 6 }\end{array}$ & \multicolumn{2}{l}{$\begin{array}{l}\text { Universidades } \\
\text { Nota 5 }\end{array}$} & \multicolumn{2}{l|}{$\begin{array}{l}\text { Universidades } \\
\text { Nota 4 }\end{array}$} \\
\hline Programas & $\begin{array}{l}\text { Professores } \\
\text { Permanentes }\end{array}$ & Programas & $\begin{array}{l}\text { Professores } \\
\text { Permanentes }\end{array}$ & Programas & $\begin{array}{l}\text { Professores } \\
\text { Permanentes }\end{array}$ \\
\hline PUC MG & 43 & $\begin{array}{l}\text { Ciências } \\
\text { Criminais } \\
\text { PUCRS }\end{array}$ & 16 & FADISP & 8 \\
\hline PUC RS & 14 & PUC PR & 13 & FDV & 11 \\
\hline UFMG & 32 & UFPB JP & 14 & ITE & 13 \\
\hline UFSC & 29 & UFRGS & 15 & PUC RJ & 17 \\
\hline UFPR & 23 & UNESA & 10 & UERJ & 36 \\
\hline UNB & 24 & UNICEUB & 15 & UFBA & 14 \\
\hline UNISINOS & 12 & UNIFOR & 16 & UFC & 9 \\
\hline USP & 139 & UNISC & 13 & UFPE & 17 \\
\hline & & UNIVALI & 10 & UNISANTOS & 14 \\
\hline & & UPM & 17 & PUC SP & 78 \\
\hline
\end{tabular}

Fonte: http://www.capes.gov.br.

O corpo docente permanente destes 29 programas era composto por 685 professores que a condição de permanentes nos três anos consecutivos do triênio 2010-2012. Desse total, apenas 134 professores publicaram em periódicos estrangeiros.

A produção científica estrangeira destes 134 docentes entre 2010 e 2012, totalizava inicialmente 278 artigos publicados, porém foram identificados problemas nos lançamentos dos dados no Coleta Capes, o que acabou gerando a necessidade de descartar 57 artigos do corpus, conforme Quadro 2. 
Quadro 2 - Exclusão de artigos por problemas no lançamento do Coleta Capes

\begin{tabular}{|l|c|}
\hline Problemas apresentados & Quant. \\
\hline $\begin{array}{l}\text { Duplicidade de publicações devido a presença de docentes credenciados em mais } \\
\text { de um PPGD }\end{array}$ & 18 \\
\hline Lançamento de dados fora do triênio analisado & 13 \\
\hline Duplicidade de lançamento dos dados & 10 \\
\hline Publicações que não eram artigos científicos & 9 \\
\hline Publicação duplicada & 5 \\
\hline Publicações que não constavam nas revistas & 2 \\
\hline Total & $\mathbf{5 7}$ \\
\hline
\end{tabular}

Fonte: Dados da pesquisa (2017).

Com a exclusão dos 57 artigos mencionados no Quadro 2, restaram 221 artigos contidos em 148 títulos de periódicos. Destes, 25 títulos foram retirados, pois pertenciam a outras áreas do conhecimento, reduzindo a listagem a 123 títulos pertencentes à área do Direito ${ }^{4}$.

Analisando os idiomas aceitos para publicação nesses periódicos verificou-se que a preferência dos pesquisadores recaiu nos títulos que aceitavam artigos na língua espanhola (33\%), seguido da língua inglesa (19\%), dos periódicos bilíngues (14\%) e multilíngues (11\%), sendo os demais $23 \%$ distribuídos em outras línguas, conforme a Tabela 4.

Tabela 4 - Idiomas aceitos para publicação.

\begin{tabular}{lc}
\hline IDIOMA & REGISTROS \\
\hline Espanhol & 41 \\
Inglês & 24 \\
Bilíngue & 17 \\
Multilíngue & 14 \\
Alemão & 7 \\
Português & 7 \\
Francês & 6 \\
Italiano & 6 \\
Húngaro & 1 \\
\hline TOTAL & $\mathbf{1 2 3}$ \\
\hline
\end{tabular}

Fonte: Dados da pesquisa (2017).

Os principais países de edição destes 123 títulos foram Espanha (15\%), Alemanha (12\%), Argentina (10\%), Itália (8\%), Holanda (7\%), Portugal (7\%), Colômbia (6\%), Estados Unidos (6\%), França (5\%), México (3\%) e Peru (3\%), conforme se observa na Tabela 5.

\footnotetext{
3 Publicação duplicada acontece "quando os autores enviam o mesmo trabalho para diversos periódicos" (GIMENEZ; GIMENEZ; BORTULUCCE, 2015, p.1).

${ }^{4} \mathrm{O}$ critério de classificação desses títulos foi a partir de consulta ao website dos periódicos, analise da descrição dos objetivos, público e definição de área a que se destinam.
} 
Tabela 5 - Distribuição geográfica das editoras dos títulos publicados.

\begin{tabular}{lc}
\hline PAÍS & REGISTROS \\
\hline Espanha & 19 \\
Alemanha & 15 \\
Argentina & 12 \\
Itália & 10 \\
Holanda & 9 \\
Portugal & 8 \\
Colômbia & 7 \\
Estados Unidos & 7 \\
França & 6 \\
México & 4 \\
Peru & 4 \\
Outros & 22 \\
\hline TOTAL & $\mathbf{1 2 3}$ \\
\hline
\end{tabular}

Fonte: Dados da Pesquisa (2017).

Os periódicos usados pelos pesquisadores para publicar estão divididos em dois modelos de negócio: formato digital e formato impresso. Os títulos em formato digital estão divididos em acesso aberto e em assinatura, conforme a Tabela 6.

Tabela 6 - Modelo de Negócio dos títulos publicados.

\begin{tabular}{lc}
\hline MODELO DE NEGÓCIO & REGISTROS \\
\hline Acesso aberto & 59 \\
Assinatura & 48 \\
Impresso & 16 \\
\hline TOTAL & $\mathbf{1 2 3}$ \\
\hline
\end{tabular}

Fonte: Dados da pesquisa (2017).

Para identificar os artigos citados pelos docentes, foram considerados os 221 artigos identificados na etapa anterior, não diferenciando os que haviam sido publicados em periódicos da área do Direito ou em periódicos de outras áreas. Essa decisão metodológica se justificou com base na ideia de que um pesquisador da área do Direito que publique em qualquer área necessita consultar e citar material bibliográfico da sua área de origem.

Em relação a esse corpus de 221 artigos, não foi possível localizar o texto completo de 27 textos. Desta forma, foram analisados 194 artigos publicados entre 2010 e 2012 pelos pesquisadores brasileiros da área do Direito em periódicos estrangeiros, identificando-se 512 artigos citados. Todos esses 512 artigos foram publicados em periódicos da área do Direito e estavam contidos em 280 títulos de periódicos da área do Direito. 


\section{ARTIGO}

Analisando os idiomas aceitos para publicação nesses 280 periódicos, identificaram-se três idiomas predominantes: inglês, espanhol e alemão, conforme a Tabela 7.

Tabela 7 - Idiomas aceitos para publicação nos títulos citados.

\begin{tabular}{lc}
\hline IDIOMA & REGISTROS \\
\hline Inglês & 191 \\
Espanhol & 31 \\
Alemão & 17 \\
Italiano & 14 \\
Francês & 13 \\
Multilingue & 8 \\
Português & 5 \\
Grego & 1 \\
\hline TOTAL & $\mathbf{2 8 0}$ \\
\hline
\end{tabular}

Fonte: Dados da pesquisa (2017).

Os principais países de edição desses 280 títulos de periódicos foram os Estados Unidos, o Reino Unido e a Alemanha, conforme a Tabela 8.

Tabela 8 - Distribuição geográfica das editoras dos títulos citados.

\begin{tabular}{lc}
\hline PAÍS & REGISTROS \\
\hline Estados Unidos & 121 \\
Reino Unido & 31 \\
Alemanha & 22 \\
Holanda & 19 \\
Espanha & 18 \\
Itália & 15 \\
França & 10 \\
Canadá & 6 \\
Colômbia & 5 \\
Portugal & 5 \\
Argentina & 4 \\
Austrália & 4 \\
México & 4 \\
Outros & 16 \\
\hline TOTAL & $\mathbf{2 8 0}$ \\
\hline
\end{tabular}

Fonte: Dados da pesquisa (2017).

Os periódicos citados pelos pesquisadores em suas publicações do período também podem ser divididos em dois modelos de negócio: formato digital e formato impresso. Os títulos em formato digital estavam divididos em acesso aberto e em assinatura, conforme a Tabela 9. 
Tabela 9 - Modelo de Negócio adotado pelos periódicos citados

\begin{tabular}{lc}
\hline MODELO DE NEGÓCIO & REGISTROS \\
\hline Assinatura & 130 \\
Acesso aberto & 118 \\
Impresso & 32 \\
\hline TOTAL & $\mathbf{2 8 0}$ \\
\hline
\end{tabular}

Fonte: Dados da pesquisa (2017).

Para verificar a disponibilidade desses títulos de periódicos estrangeiros no Portal da Capes foi necessário consolidar em uma única listagem os títulos usados pelos pesquisadores para publicar (123 títulos) com os títulos onde foram publicados os artigos citados (280 títulos). Retirando-se as duplicidades, obteve-se uma lista com 368 títulos.

Essa lista consolidada também apresentou dois principais modelos de negócio: o primeiro no formato digital (324 títulos) e o segundo no formato impresso (44 títulos). Os títulos em formato digital estavam divididos em periódicos de acesso aberto (162 títulos) e periódicos que exigiam assinatura (162 títulos), conforme demonstrado na Tabela 10.

Tabela 10 - Modelo de negócio da lista consolidada

\begin{tabular}{lcc}
\hline MODELO DE NEGÓCIO & REGISTROS & PERCENTUAL \\
\hline Acesso Aberto & 162 & $44 \%$ \\
Assinatura & 162 & $44 \%$ \\
Impresso & 44 & $12 \%$ \\
\hline TOTAL & 368 & $100 \%$ \\
\hline
\end{tabular}

Fonte: Dados da pesquisa (2017)

Analisando os 162 títulos em formato digital que requeriam assinatura, observou-se que 57 deles estavam disponíveis no Portal da Capes, sendo que quatro títulos, pelo menos durante o período desta pesquisa, não estavam classificados na área do Direito, embora os editores indicassem que se destinavam à área. Sendo assim, da listagem de títulos estrangeiros da área do Direito extraída do Portal em 2015, 53 títulos foram caracterizados como de interesse dos pesquisadores da área, indicando que situou-se em 7,6\% a demanda dos pesquisadores da área do Direito versus a oferta de títulos estrangeiros assinados pelo Portal.

\section{CONSIDERAÇÕES FINAIS}

O Estado foi o principal responsável por elaborar e implementar as políticas públicas que orientaram as pesquisas em ciência e tecnologia entre o período de 1950 até o fim da década 
de 1980 (GONZÁLEZ DE GOMÉZ, 2002). A partir da popularização das novas tecnologias, o discurso econômico passou a prevalecer e as preocupações recaíram sobre a geração, processamento e transmissão da informação, em especial a informação em meio digital, como fonte fundamental para o aumento da produtividade (CASTELLS, 2012). O Portal de Periódicos da Capes surgiu neste contexto como uma ação voltada para resolver o problema da falta de recursos para a aquisição e acesso dos cientistas brasileiros aos periódicos científicos internacionais.

Esta pesquisa estudou o Portal de Periódicos da Capes a partir dos conceitos defendidos por González de Gómez (2002) e por Secchi (2014). Com base no quadro referencial desses autores infere-se que a construção do Portal de Periódicos da Capes como uma política pública aconteceu a partir de uma ação tácita, voltada à modificação do regime de informação vigente cujo lócus de manifestação foi o Estado.

Após mensurar a contribuição dos títulos estrangeiros assinados pelo Portal de Periódicos da Capes para a produção científica dos pesquisadores da área do Direito no período de 2010 a 2012, constatou-se a pequena participação desses títulos nas pesquisas desenvolvidas pelos docentes da área do Direito. Os resultados obtidos permitem fazer algumas inferências sobre essa baixa contribuição do Portal para a produção da área. Em primeiro lugar verifica-se o fato da área ainda usar bastante os periódicos impressos. Também se observa que metade dos periódicos em formato digital utilizados pelos pesquisadores está disponível em acesso aberto, permitindo seu acesso independentemente do Portal. Porém também é possível verificar que existe um número significativo de títulos de periódicos estrangeiros que seriam do interesse dos pesquisadores da área e que necessitariam ser assinados pelo Portal para garantir o acesso ao seu conteúdo.

Recomenda-se, portanto, adequar a coleção especializada em Direito do Portal de Periódicos da Capes aos hábitos informacionais e às preferências da comunidade científica do Direito. Também seria indicado ampliar os treinamentos de usuários na área, para que os pesquisadores assumam maior protagonismo na indicação dos títulos assinados.

Esta pesquisa não teve a pretensão de esgotar a temática. Apesar de sua abrangência, sua principal limitação decorre do fato de restringir-se à produção relativa ao triênio de 20102012. Sendo assim, recomenda-se a continuidade dos estudos sobre a área do Direito para uma maior compreensão deste domínio do conhecimento. 


\section{REFERÊNCIAS}

ALMEIDA, Elenara Chaves Edler de; GUIMARÃES, Jorge Almeida. A pós-graduação e a evolução da produção científica brasileira. São Paulo: Senac, 2013.

ALMEIDA, Elenara Chaves Edler de; GUIMARÃES, Jorge Almeida; ALVES, Isabel Teresa Gama. Dez anos do Portal de Periódicos da Capes: histórico, evolução e utilização. Revista Brasileira de Pós-Graduação, v. 7, n. 13, p. 218-246, 2010. Disponível em:

http://ojs.rbpg.capes.gov.br/index.php/rbpg/article/view/194/188. Acesso em: 12 maio. 2015.

AMORIM, Antonio Carlos. A globalização do mercado de periódicos científicos eletrônicos e os consórcios de bibliotecas universitárias brasileiras: desafios à democratização do conhecimento científico. 2002. 147 f. Dissertação (Mestrado em Ciências da Comunicação) - Departamento de Ciências da Informação e Documentação, Universidade de São Paulo, 2002.

BRASIL. Ministério da Educação. Portaria nº 287, de 24 de abril de 1986. Diário Oficial, Brasília, 28 abril 1986b. Seção I, p. 6050-6052.

BRASIL. Ministério da Educação. Portaria nº 288, de 24 de abril de 1986. Diário Oficial, Brasília, 25 abril 1986a. Seção I, p. 6000-6001.

BRASIL. Ministério da Educação. Secretaria da Educação Superior. Portaria no 55, de 28 de abril de 1986c. Diário Oficial, Brasília, 30 abril 1986c. Seção I, p. 6224-6225.

CAETANO, Ana Carolina de Souza. Politicas publicas para bibliotecas universitárias: um olhar sobre os resultados do PNBu (1986). In: SEMINÁRIO NACIONAL DE

BIBLIOTECAS UNIVERSITÁRIAS, 17, 2012, Porto Alegre. Anais... Porto Alegre: Universidade Federal do Rio Grande do Sul, 2012.

CASTELLS, Manuel. A sociedade em rede: volume 1. São Paulo: Paz e Terra, 2012.

CHASTINET, Yone. Participação da comunidade na implantação do Plano Nacional de Bibliotecas Universitárias - PNBU. In: SEMINÁRIO NACIONAL DE BIBLIOTECAS UNIVERSITÁRIAS, 6, 1989, Belém. Anais... Belém: Universidade Federal do Pará, Biblioteca Central; MEC SESU, 1990. v. 2, p. 38-47.

CHORÃO, Luís Bigotte. O periodismo jurídico português do século XIX: páginas de história da cultura nacional oitocentista. Lisboa: Imprensa Nacional, Cada da Moeda, 2002.

CORREA, Cynthia Harumi Watanabe et al. Portal de periódicos da CAPES: um misto de solução financeira e inovação. Revista Brasileira de Inovação, Rio de Janeiro, v.7, n.1, p.127-145, jan./jun. 2008.

CUNHA, Murilo Bastos da; DIÓGENES, Fabiene Castelo Branco. A trajetória da biblioteca universitária no Brasil no período de 1901 a 2010. Encontros Bibli: revista eletrônica de Biblioteconomia e Ciência da Informação, v. 21, n. 47, p.100-123, set./dez., 2016.

FERNANDES, Wesley Rodrigo; CENDÓN, Beatriz Valadares. Portal de Periódicos da Capes: proposta de um modelo de estudo bibliométrico para avaliação da coleção. Revista Brasileira de Pós-Graduação, Brasília, v. 7, n. 13, p. 318 - 349, nov. 2010. 


\section{ARTIGO}

INOVAÇÃo

FERRAZ JUNIOR, Tercio Sampaio. O Direito como objeto de conhecimento: perfil histórico. In: FERRAZ JUNIOR, Tercio Sampaio. Introdução ao estudo do direito: técnica decisão, dominação. São Paulo: Atlas, 2015, p. 31-56.

FERREIRA, Sueli Mara S. P.; SOUTO, Leonardo Fernandes. Dos sistemas de informação federados à federação de bibliotecas digitais. Revista Brasileira de Biblioteconomia e Documentação, Nova Série, v. 2, n. 1, p.23-40, jan./jun. 2006. Disponível em: https://rbbd.fe bab.org.br/rbbd/article/viewFile/3/20. Acesso em: 23 jan. 2017.

FONSECA, Maria Guadalupe Piragibe da. Modelos de pesquisa jurídica. In: FONSECA, Maria Guadalupe Piragibe da. Iniciação à pesquisa no direito: pelos caminhos do conhecimento e da invenção. Rio de Janeiro: Elsevier, 2009, p. 37-44.

FORMIGA, Armando Soares de Castro. O período jurídico oitocentista na órbita das academias Brasileiras. Revista Integralização Universitária, v.1, n.1, abr./set. 2007.

FORMIGA, Armando Soares de Castro. Periodismo jurídico no Brasil do século XIX: história do Direito em jornais e revistas. Curitiba: Juruá, 2010.

GARCIA, Maria Lúcia Andrade. A informação científica e tecnológica no Brasil. Ciência da Informação, Brasília, v. 9, n. 1/2, p. 41-81, 1980.

GARCIA, Maria Lúcia Andrade. Plano nacional de bibliotecas universitárias: planejamento e permanência. [Brasília: Finep], 1991. 42 f.

GONZÁLEZ DE GOMÉZ, Maria Nélida. Novos cenários políticos para a informação. Ciência da Informação, Brasília, v. 31, n. 1, p. 27-40, jan./abr. 2002.

GONZÁLEZ DE GOMÉZ, Maria Nélida. Regime de informação: construção de um conceito. Informação \& Sociedade: Estudos, João Pessoa, v.22, n.3, p.43-60, set./dez. 2012.

LUBISCO, Nidia Maria Lienert. A biblioteca universitária no processo de "avaliação das condições de oferta" dos cursos de graduação pelo MEC: o caso da UFBA. 2011. 279f. Dissertação (Mestrado em Ciência da Informação) - Instituto de Ciência da Informação, Universidade Federal da Bahia, 2011.

MARTINHO, Ana Maria de Sá Osório Figueiredo. Contributo das revistas jurídicas para a comunicação e criação de conhecimento: uma perspectiva bibliométrica. 264f. Tese (Doutorado em Bibliografía y Documentación Retrospectiva en Humanidades) Programa de Doctorado: D264: Bibliografía y Documentación Retrospectiva en Humanidades. Departamento de Ciencias Sanitarias y Médico-Sociales. Universidad de Alcalá, Alcalá de Henares, 2011.

ODDONE, Nanci; MEIRELLES, Rodrigo. O Portal de Periódicos da Capes e os indicadores de desempenho da informação eletrônica. DataGramaZero: Revista de Ciência da Informação, v. 7, n.3, jun. 2006.

ORTELLADO, Pablo. As políticas nacionais de acesso à informação científica. Liinc em Revista. Rio de Janeiro, v. 4, n. 2, p. 186-195, 2008. Disponível em: http://revista.ibict.br/liin c/article/view/3164/2830. Acesso em: 16 jan. 2017. 
RAMOS, Henrique Cesar Monteiro Barahona. O periodismo jurídico brasileiro no século XIX. Revista Internacional de História Política e Cultura Jurídica, Rio de Janeiro, v. 2, n. 2, p. 54-97, jan. 2010.

SECCHI, Leonardo. Políticas públicas: conceitos, esquemas de análise, casos práticos. 2.ed. São Paulo: Cengage Learning, 2014.

SILVA, Angela Maria Moreira. A construção das bibliotecas universitárias no Brasil. Revista Informação \& Universidade (RevIU), v. 2, n. 1, 2010. Disponível em: https://www.research gate.net/publication/259345328_A_construcao_das_bibliotecas_universitarias_no_Brasil. Acesso em: 05 nov. 2016.

SILVA, Edilene Maria. A influência das políticas de informação científica e tecnológica para as bibliotecas universitárias. 2009. 103 f. Dissertação (Mestrado em Ciência da Informação) - Universidade Federal da Paraíba, João Pessoa, 2009. 